DIW BERLIN

Discussion

Papers

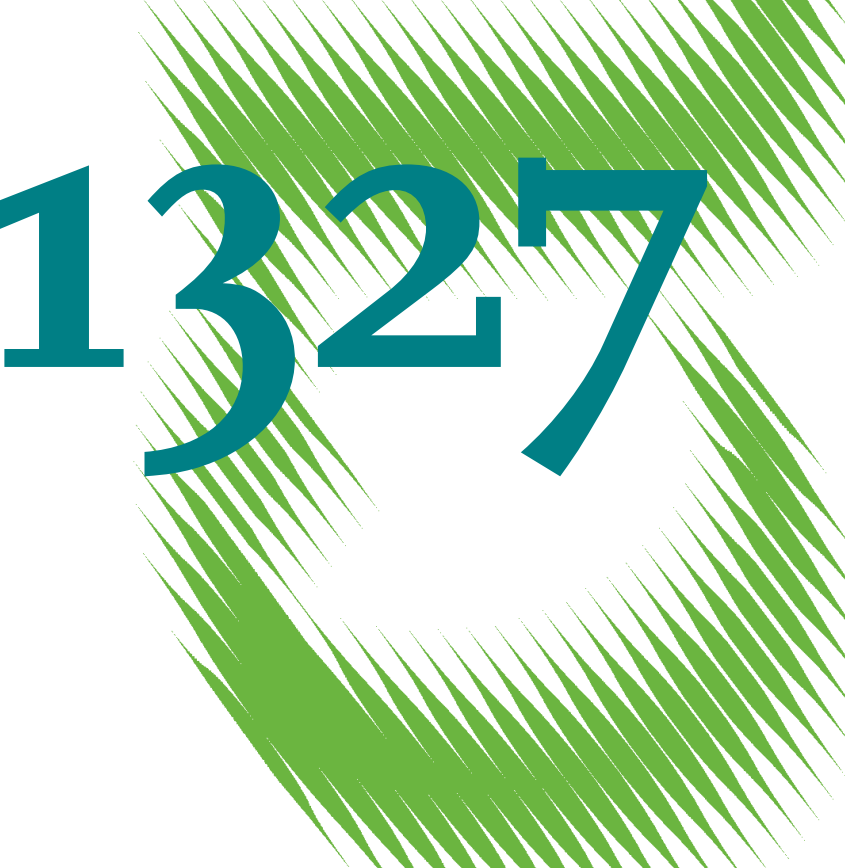

On Distributive Effects of Optimal Regulation for Power Grid Expansion 
Opinions expressed in this paper are those of the author(s) and do not necessarily reflect views of the institute.

IMPRESSUM

(C) DIW Berlin, 2013

DIW Berlin

German Institute for Economic Research

Mohrenstr. 58

10117 Berlin

Tel. $+49(30) 89789-0$

Fax +49 (30) $89789-200$

http://www.diw.de

ISSN print edition $1433-0210$

ISSN electronic edition 1619-4535

Papers can be downloaded free of charge from the DIW Berlin website:

http://www.diw.de/discussionpapers

Discussion Papers of DIW Berlin are indexed in RePEc and SSRN:

http://ideas.repec.org/s/diw/diwwpp.html

http://www.ssrn.com/link/DIW-Berlin-German-Inst-Econ-Res.html 


\title{
On Distributive Effects of Optimal Regulation for Power Grid Expansion
}

\author{
Luis Ángel Herrera ${ }^{1}$ and Juan Rosellón ${ }^{2}$
}

\begin{abstract}
To date, the distributive implications of incentive regulation on electricity transmission networks have not been explicitly studied in the literature. More specifically, the parameters that a regulator might use to achieve distributive efficiency under price-cap regulation have not yet been identified. To discern these parameters is the motivation for the research presented in this paper. We study how different weight parameters affect the distributive characteristics of optimal price-cap incentive regulation for electricity transmission. We find that a regulator's use of ideal (Laspeyres) weights tends to be more beneficial for the Transco (consumers) than for consumers (the Transco).
\end{abstract}

Keywords Electricity transmission; incentive regulation; distributive efficiency.

JEL Classification L50; L51; L94; Q40; Q42.

We thank the valuable research assistantship from David DeMiglio.

\footnotetext{
${ }^{1}$ CIDE, Carretera México-Toluca 3655 Col. Lomas de Santa Fe 01210 México, D.F., luisangelhf@gmail.com.

${ }^{2}$ CIDE, Department of Economics, Carretera México-Toluca 3655 Col. Lomas de Santa Fe 01210 México, D.F. and DIW Berlin, Department of Energy, Transportation, Environment, jrosellon@diw.de. Juan Rosellón acknowledges support from a Marie Curie International Incoming Fellowship within the 7th European Community Framework Programme, and from Conacyt (p. 131175).
} 


\section{Introduction}

Electricity transmission is a market that, generally speaking, moves towards natural-monopoly characteristics that then counteract full market efficiency as well as optimal social welfare. For this reason, the transmission of electricity requires oversight through regulation over certain components of the market. On one hand, a transmission company (Transco) normally has poor incentives to expand the electric grid due to revenues accruing from short-run congestion rents. On the other hand, an efficient expansion of the transmission network is crucial for optimal productive resource allocation and fair market prices. However, an inefficient transmission network poses congestion problems such as as higher final costs of electricity, which has negative repercussions not only for the electric sector but the wider economy.

In response to this problem, various regulatory mechanisms have been proposed in the literature to promote transmission investment. One such framework is the Hogan-Rosellón-Vogelsang (HRV) mechanism, described in Hogan et al (2010, HRV). This structure combines merchant and regulatory approaches to promote investment in electricity networks. Allocative-efficient transmission investment is incentivized through intertemporally rebalancing the fixed and variable charges included in the Transco's two-part tariff, all within a nodal pricing system employing financial transmission rights (FTRs).

The primary goal here is to create efficient transmission networks that achieve optimum social welfare, while maximizing Transco revenues so as to incentivize expansion investment. Without expansion of the network, inefficient networks allow Transcos to earn congestion rents through higher costs charged to end consumers. In efficient transmission networks, congestion rents are redistributed favoring the consumer, allowing for transmission prices to converge down to marginal cost, or Ramsey pricing. This creates a boon to all economic sectors due to lower realized energy costs. Transcos are typically unwilling to lower congestion because it affords them increased revenues, but through an efficient incentive structure Trancos can be compelled to invest in transmission expansion to their own benefit and to that of consumers.

However, the distributive implications of incentive regulation on transmission networks have not been widely studied in the literature. More specifically, the parameters that a regulator might use to achieve distributive efficiency have so far not been explicitly analyzed. This is the motivation for the research presented in this paper. We analyze how different weight parameters affect the distributive characteristics of the HRV incentive regulatory mechanism, as well as present analytically the effects of said variables. 
This document is organized as follows. In section 1, we present the HRV model. Section 2 applies the HRV model to a stylized network in two periods, using both Laspeyres and ideal weights. In section 3, we present in detail the analytical conditions that characterize the distributive effects of each type of weight. Numerical examples are also provided. Section 4 concludes with a discussion of our findings.

\section{The HRV Model}

In the following pages we address the distributive efficiency implications of the HRV price-cap incentive mechanism which combines price cap regulation and FTRs with price-taking generators and consumers. The effects of physical constraints on electricity flows (given by the Kirchhoff laws) are considered as well as the topology of transmission networks. The HRV model redefines the output of the Transco in terms of point-to-point transactions given by long-term FTR obligations (LTFTRs). The Transco chooses variable and fixed charges so as to maximize profits subject to a price-cap constraint over its two-part tariff, following the regulatory logic in Vogelsang (2001). The fixed portion of the tariff can be seen as a complementary charge to recover fixed costs of generation and transmission (as in Rubio-Odériz and Pérez-Arriaga, 2000). The variable portion actually points to the price of the FTR based on nodal price differences. While Vogelsang (2001) is in principle only applicable to radial lines, the HRV mechanism is an upgrade designed to also deal with meshed transmission networks.

Mathematically, the HRV is a bi-level programming model. The upper level problem models the Transco's profit maximization subject to a price-cap constraint that usually relies upon the use of previous period quantity weights (Laspeyres) or ideal quantity weights (proposed in Laffont and Tirole, 1996). The lower level problem is actually a power-flow program where an independent system operator (ISO) maximizes social welfare subject to generation, line-capacity and energy balance constraints in order to achieve maximal production of and revenue from dispatched electricity generation.

In the HRV regulatory model, the expansion of the transmission network naturally implies a reduction of the congestion rents accruing to the Transco. The Transco might compensate such revenue reductions with an increase in the fixed charge portion of its two-part tariff that are constrained by a price cap. As shown in various applications of the HRV model, such increases in the fixed charge may result in overly high price levels. Such issues are critical when considering real-world applications. 


\subsection{Upper Level}

In the upper level of the HRV model, the Transco maximizes its profits subject to an intertemporal price-cap constraint:

$$
\max _{k, F} \pi=\sum_{t}^{T}[\overbrace{\sum_{i j} \tau_{i j}^{t}(k) q_{i j}^{t}(k)}^{A}+\overbrace{F^{t} N^{t}}^{B}-\overbrace{\sum_{i j} c\left(k_{i j}^{t}\right)}^{C}] ; \quad i \neq j
$$

subject to:

$$
\sum_{i j} \tau_{i j}^{t}(k) q_{i j}^{w}(k)+F^{t} N^{t} \leq(1+R P I+X)\left[\sum_{i j} \tau_{i j}^{t-1}(k) q_{i j}^{w}(k)+F^{t-1} N^{t}\right]
$$

The objective function (1) of this problem runs over $\mathrm{T}$ periods with line capacities $k$ and fixed charge $F$ as choice variables. It consists of two revenue sources, (A) and (B), as well as of a cost term, (C). Term (A) represents congestion rents, which are defined by the FTR point-to-point transactions, $q_{i j}^{t}$, between nodes $i$ and $j$, multiplied by the FTR auction price, $\tau_{i j}^{t}$. The second term (B) denotes the fixed fee that is charged to the $N$ users of the transmission network, and the third term, (C), is the cost $c\left(k_{i j} t\right)$ faced by the Transco due to the line expansion between nodes $i$ and $j$. The regulatory constraint (2) is a cap over the Transco's two-part tariff with efficiency $X$ and inflation $R P I$ adjustments. The regulator choses the weights $w$ in order to promote the convergence of the mechanism to an allocative-efficient steady state equilibrium (see Vogelsang, 2001). The ability to rebalance the two parts of the tariff guarantees that the Transco achieves individual rationality during the expansion of the transmission network, even under decreasing congestion rents.

In order to avoid working explicitly with the profits from the auctions of FTRs, the program given by (1) and (2) is usually redefined in terms of capacity investment as a choice variable (as opposed to the variable fee of the two-part tariff) (see Hogan et al, 2010):

$$
\max _{k, F} \pi=\sum_{t}^{T}\left[\sum_{i}^{I}\left(p_{i}^{t} d_{i}^{t}-p_{i}^{t} g_{i}^{t}\right)+F^{t} N^{t}-\sum_{i j}^{I} c\left(k_{i j}^{t}\right)\right]
$$

subject to:

$$
\sum_{i}^{I}\left(p_{i}^{t} d_{i}^{w}-p_{i}^{t} g_{i}^{w}\right)+F^{t} N^{t} \leq(1+R P I+X)\left[\sum_{i}^{I}\left(p_{i}^{t-1} d_{i}^{w}-p_{i}^{t-1} g_{i}^{w}\right)+F^{t-1} N^{t}\right]
$$

In this way, the congestion rents and the regulatory constraint are redefined in terms of the load cost difference $p_{i} d_{i}$ and the generators'costs $p_{i} g_{i}$. 


\subsection{Lower Level}

The lower level is a social-welfare maximization problem solved by the ISO given the constraints on generation capacity and energy balance. The market is assumed to be administered competently and efficiently. The (inverse) demand function $p(d)$ is linear and the marginal cost of generation $m c$ is constant in each period $t$. This in turn guarantees simultaneous technical feasibility of electricity flows as well as adequate financial revenue (see Hogan, 2013):

$$
\max _{d, g} W=\sum_{i, t}^{I, T}\left[\int_{0}^{d_{i}^{t}} p\left(\tilde{d}_{i}^{t}\right) \mathrm{d} \tilde{d}_{i}^{t}\right]-\sum_{i, t}^{I, T} m c_{i} g_{i}^{t}
$$

subject to:

$$
\begin{array}{cc}
g_{i}^{t} \leq g_{i}^{t, \max } & \forall i, t \\
\left|p f_{i j}^{t}\right| \leq k_{i j}^{t} & \forall i, j \\
g_{i}^{t}+q_{i}^{t}=d_{i}^{t} & \forall i, t
\end{array}
$$

Constraint (6) requries that generation $g$ in node $i$ cannot be greater than the available maximum generation capacity at that node $g^{\max }$. Inequality (7) requires that the energy flow $p f_{i j}$ between nodes $i$ and $j$ cannot exceed the limits of transmission lines $k_{i j}$. Finally, equation (8) demonstrates that demand $d_{i}^{t}$ at each node must be satisfied by local generation $g_{i}^{t}$ or by net injections $q_{i}^{t}$.

At each node, net injections are obtained from the sum of power in- and outflows:

$$
q_{i}=\sum_{j} p f_{i j}
$$

Just as in Rosellón and Weight (2011), power flows are calculated on a direct current mesh net topology (DC-Load-Flow) using an economically expedient focus. With such an arrangement one can take into account the differences in voltage angle between lines as well as the susceptibility and reactivity of each line.

\subsection{Related Literature}

Rosellón and Weigt (2011) test the HRV mechanism in a simplified network in Northwest Europe and show that the model provides satisfactory results in practice. The mechanism approaches the welfare-optimal benchmark, relieves the system from congestion, and increases the profits of the Transco over time. They also show that the mechanism might be applied in a relatively easy way at a low cost, since the 
regulator requires only minimal information which is provided by market prices. Similarly, Rosellón et al (2011) apply the HRV mechanism to the Pennsylvania-New Jersey-Maryland (PJM) system characterized by high levels of congestion. They show that the mechanism promotes transmission capacity enhancement in that energy is transmitted from areas of low generation cost in the west to areas with high demand and high price in the east. Electricity prices converge to the marginal cost of generation, congestion rents decrease, and the overall social welfare increases.

Schill et al (2011) study the performance of different regulatory approaches to electricity transmission expansion in Northwestern Europe under realistic demand behavior and fluctuating wind-generation. They show that under such conditions the HRV mechanism provides better welfare results than the other alternatives (which include cost-of-service regulation as well as a lack of regulation). However, these results rely on a relatively high fixed charge that turns out to be a great deal more than congestion-rent losses, allowing a substantial increase in the Transco's total profits. That is, the Transco receives the largest welfare gains due to expansion profits, in comparison to benefits to consumers and generators. They suggest a redistribution of these benefits by moving from an allocative-efficient solution to one that favors consumers over the Transco. This could be addressed through an adequate choice of price weights in the regulatory price-cap constraint.

The distributive problem proposed in the previous paragraph is studied in Laguna (2012), in which function and demand costs are supposed to be stationary. The distributive properties of the HRV mechanism are studied in a radial network of two nodes, in two periods. The effects of the surplus of each agent are isolated and the users of the network, the generator and the consumer, pay together the fixed cost of transmission. Their results demonstrate that the surpluses of all agents are sensitive to several influences: the discount factor of the firm, the maximum price level, the regulatory restriction weights, and the cost and demand functions. In order to explicitly observe the sensitivity of the surpluses to such factors, especially to the weights, a continued simulation analysis is proposed.

Some related literature has demonstrated, however, certain effects of specific weight mechanisms. There are essentially two ways to regulate price structures: fixed weights (tariff-basket regulation) and variable weights (average-revenue regulation). Within the fixed weights framework, a maximum limit is established for an $I(p)=\sum_{i=1}^{N} w_{i} p_{i}$ consisting of prices $p_{i}$ and fixed weights $w_{i}$. Weights might be previous period (chained Laspeyres), quantities of output (or throughput), intertemporally fixed quantities (fixed Laspeyres), or projected quantities that correspond to the steady state equilibrium (ideal Laffont-Tirole weights). 
A variable-weight framework allows for more relative price variation because this form of regulation establishes a cap on income per unit without the use of maximum limits. Average-revenue regulation allows for greater flexibility in the Transco's tariff rebalancing strategy, but then lacks a method to converge to the welfare maximizing equilibrium. The literature has demonstrated that with a myopic (short-term oriented) profit maximization outlook and under stable (non-stochastic) cost and demand conditions, a chained Laspeyres index will cause firm prices to converge intertemporally to the Ramsey-Boiteaux pricing (Vogelsang 2001; Vogelsang 1989; Bertoletti and Poletti 1997; Loeb and Magat 1979; and Sibley 1989). This is accomplished by simultaneously reconciling between social welfare maximization and the individual rationality of the regulated firm. Social surplus is thereby redistributed to the monopoly Transco in such a way that long-run fixed costs are recovered, while consumer surplus is maximized over time.

We concentrate our analysis on the distributive effects owing to weight preference in a radial-line two-period model.

\section{Application of the HRV Model to a Radial Net- work}

Here we focus on a stylized radial-line topology with a fixed number $N$ of network users:

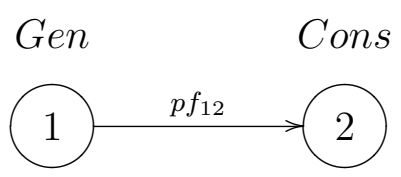

We assume that node 1 is solely a generation node and that node 2 is purely a consumption node. Additionally, we suppose a discount factor $\beta$ in the Transco's profit maximization. In this context, the upper and lower levels are specified in 2.1 and 2.3.

\subsection{Upper Level Problem}

The Transco intertemporally maximizes profits subject to the price-cap regulatory constraint and to the ISO-optimal choices in the lower-level problem: 


$$
\max _{k, F} \pi=\sum_{t=1}^{2} \beta^{t-1}\left[\left(p_{1}^{t} d_{1}^{t}-p_{1}^{t} g_{1}^{t}\right)+\left(p_{2}^{t} d_{2}^{t}-p_{2}^{t} g_{2}^{t}\right)+F^{t} N-c\left(k_{12}^{t}\right)\right]
$$

subject to:

$$
\begin{aligned}
& p_{2}^{1} d_{2}^{w 1}-p_{1}^{1} g_{1}^{w 1}+F^{1} N \leq(1+R P I+X)\left(p_{2}^{0} d_{2}^{w 1}-p_{1}^{0} g_{1}^{w 1}+F^{0} N\right) \\
& p_{2}^{2} d_{2}^{w 2}-p_{1}^{2} g_{1}^{w 2}+F^{2} N \leq(1+R P I+X)\left(p_{2}^{1} d_{2}^{w 2}-p_{1}^{1} g_{1}^{w 2}+F^{1} N\right)
\end{aligned}
$$

\subsection{Solution to Upper Level Problem}

The solution can be obtained by rewriting the Transco's maximization problem as:

$$
\max _{k, F} \pi=\sum_{t=1}^{2} \beta^{t-1}\left[\left(p_{2}^{t}-p_{1}^{t}\right) q_{2}^{t}+F^{t} N-c\left(k_{12}^{t}\right)\right]
$$

subject to:

$$
\begin{aligned}
\left(p_{2}^{1}-p_{1}^{1}\right) q^{w 1}+F^{1} N & \leq \gamma\left[\left(p_{2}^{0}-p_{1}^{0}\right) q^{w 1}+F^{0} N\right] \\
\left(p_{2}^{2}-p_{1}^{2}\right) q^{w 2}+F^{2} N & \leq \gamma\left[\left(p_{2}^{1}-p_{1}^{1}\right) q^{w 2}+F^{1} N\right]
\end{aligned}
$$

where $\gamma=1+R P I+X$.

Given that the Transco will always choose the highest possible fees, the constraints are assumed to be met equally. From (14) and (15) one can observe that:

$$
\begin{aligned}
F^{1} N & =\gamma\left[\left(p_{2}^{0}-p_{1}^{0}\right) q^{w 1}+F^{0} N\right]-\left(p_{2}^{1}-p_{1}^{1}\right) q^{w 1} \\
F^{2} N & =\gamma\left[\left(p_{2}^{1}-p_{1}^{1}\right) q^{w 2}+F^{1} N\right]-\left(p_{2}^{2}-p_{1}^{2}\right) q^{w 2} \\
& =(\gamma)^{2}\left[\left(p_{2}^{0}-p_{1}^{0}\right) q^{w 1}+F^{0} N\right]+\gamma\left(p_{2}^{1}-p_{1}^{1}\right)\left(q^{w 2}-q^{w 1}\right)-\left(p_{2}^{2}-p_{1}^{2}\right) q^{w 2}
\end{aligned}
$$

Substituting the obtained values for $F^{1} N$ and $F^{2} N$ into (13), we end up with an unconstrained maximization problem with choice variables $k_{12}^{1}$ and $k_{12}^{t}$. The next step implies choosing different types of weights and substituting the optimal results from the lower level problem into the Transco's objective function. We will concentrate our analysis on Laspeyres (previous-period) weights and ideal weights. The expansion $\operatorname{costs} c(\cdot)$ are specified via the linear function $c\left(k_{12}^{t}\right)=\operatorname{ecf}\left(k_{12}^{t}-k_{12}^{t-1}\right)$, in which we assume a constant expansion cost factor ecf; given that a reduction in line capacity is quite costly, we assume $k_{12}^{1} \leq k_{12}^{2}$. That is, we will only allow for expansions in network capacity. Additionally, so that a network expansion makes economic sense, we assume $q_{2}^{0} \leq \frac{a-m c_{1}}{b}$. 


\subsection{Lower Level Problem}

The ISO's welfare maximization and dispatch optimization problem is:

$$
\max _{d, g} W=\sum_{t=1}^{2} \int_{0}^{d_{2}^{t}} p_{2}\left(\tilde{d}_{2}^{t}\right) \mathrm{d} \tilde{d}_{2}^{t}-\sum_{t=1}^{2} m c_{1} g_{1}^{t}
$$

Subject to the restrictions:

$$
\begin{aligned}
g_{1}^{t} & \leq g_{1}^{t, \max } \\
\left|p f_{12}^{t}\right| & \leq k_{12}^{t} \\
g_{1}^{t}+q_{1}^{t} & =d_{1}^{t} \\
g_{2}^{t}+q_{2}^{t} & =d_{2}^{t}
\end{aligned}
$$

With given injections:

$$
\begin{aligned}
q_{1}^{t} & =\sum_{j} p f_{1 j}^{t}=p f_{12}^{t} \\
q_{2}^{t} & =\sum_{j} p f_{2 j}^{t}=p f_{21}^{t}=-p f_{12}^{t}
\end{aligned}
$$

\subsection{Solution to Lower Level Problem}

The solution to this problem is obtained as follows. Our assumptions imply $d_{1}^{t}=0$ and $g_{2}^{t}=0$, then from (21) and (22)

$$
\begin{aligned}
& g_{1}^{t}=-q_{1}^{t} \\
& d_{2}^{t}=q_{2}^{t}
\end{aligned}
$$

Using (23) and (24) we conclude that:

$$
g_{1}^{t}=d_{2}^{t}=q_{2}^{t}
$$

Therefore, the problem can be rewritten as:

$$
\max _{q_{2}^{t}} W=\sum_{t=1}^{2} \int_{0}^{q_{2}^{t}} p_{2}\left(\tilde{q}_{2}^{t}\right) \mathrm{d} \tilde{q}_{2}^{t}-\sum_{t=1}^{2} m c_{1} q_{2}^{t}
$$

subject to:

$$
\begin{aligned}
& q_{2}^{t} \leq g_{1}^{t, \max } \\
& q_{2}^{t} \leq k_{12}^{t}
\end{aligned}
$$


If we further assume that there is enough generation capacity in node 1 and we explicitly write the inverse linear demand function at node 2 as $p_{2}\left(d_{2}^{t}\right)=a-b d_{2}^{t}$, the solution to the lower level problem is given by:

$$
\begin{gathered}
q_{2}^{t}\left(k_{12}^{t}\right)=\left\{\begin{array}{r}
k_{12}^{t} \quad \text { if } k_{12}^{t} \leq \frac{a-m c_{1}}{b} \\
\frac{a-m c_{1}}{b} \quad \text { in other case }
\end{array}\right. \\
p_{2}^{t}\left(k_{12}^{t}\right)=\left\{\begin{array}{r}
a-b k_{12}^{t} \quad \text { if } k_{12}^{t} \leq \frac{a-m c_{1}}{b} \\
m c_{1} \quad \text { in other case }
\end{array}\right. \\
p_{1}^{t}=m c_{1}
\end{gathered}
$$

It can be observed that the ISO would like to set $q_{2}^{t}=\frac{a-m c_{1}}{b}$, but such a decision will be constrained by transmission capacity $k_{12}^{t}$. In the following sections, we derive concrete solutions to these bi-level programming problems and apply either Laspeyres or ideal weights.

\subsection{Laspeyres Weights}

The first type of weight that we test is the previous-period Laspeyres weight given by $q^{w}=q^{t-1}$. Using the expressions(13) to (17) we can determine the Transco's problem of interest. This yields:

$$
\max _{k_{12}^{1}, k_{12}^{2}} \beta\left(p_{2}^{2}-p_{1}^{2}\right)\left(q_{2}^{2}-q_{2}^{1}\right)+(1+\beta \gamma)\left(p_{2}^{1}-p_{1}^{1}\right)\left(q_{2}^{1}-q_{2}^{0}\right)-\beta e c f k_{12}^{2}-(1-\beta) e c f k_{12}^{1}+\pi_{0}
$$

where $\pi_{0}:=\left(\gamma+\beta \gamma^{2}\right)\left[\left(p_{2}^{0}-p_{1}^{0}\right) q_{2}^{0}+F^{0} N\right]+e c f k_{12}^{0}$.

In order to solve the complete bi-level problem, we substitute the solution values obtained from the lower level into the upper level.(The complete derivation can be found in Appendix A.)

The optimal capacities in the upper level problem are then given by:

$$
k_{12}^{1}=\left\{\begin{array}{cl}
\frac{\left(a-m c_{1}+b q_{2}^{0}\right)(1+\beta \gamma)-e c f}{2 b(1+\beta \gamma)} & \text { if } q_{2}^{0}>\hat{q} \\
\frac{2\left(a-m c_{1}+b q_{2}^{0}\right) \beta \gamma-(a-m c-e c f) \beta+2\left(a-m c+b q_{2}^{0}-e c f\right)}{b(4-\beta+4 \beta \gamma)} & \text { in other case }
\end{array}\right.
$$


$k_{12}^{2}=\left\{\begin{array}{cl}\frac{\left(a-m c_{1}+b q_{2}^{0}\right)(1+\beta \gamma)-e c f}{2 b(1+\beta \gamma)} & \text { if } q_{2}^{0}>\hat{q} \\ \frac{\left(3 a-3 m c+b q_{2}^{0}-2 e c f\right) \beta \gamma-(a-m c-e c f) \beta+3 a-3 m c+b q_{0}^{2}-3 e c f}{b(4-\beta+4 \beta \gamma)} & \text { in other case }\end{array}\right.$

where $\hat{q}=\frac{\left(a-m c_{1}\right)(1+\beta \gamma)-e c f(1+2 \beta \gamma)}{b(1+\beta \gamma)}$.

The fixed tariff charges are given by:

$$
\begin{aligned}
& F^{1} N=\gamma\left[\left(p_{2}^{0}-p_{1}^{0}\right) q_{2}^{0}+F^{0} N\right]-\left(a-b k_{12}^{1}-m c_{1}\right) q_{2}^{0} \\
& F^{2} N=(\gamma)^{2}\left[\left(p_{2}^{0}-p_{1}^{0}\right) q_{1}^{0}+F^{0} N\right]+\gamma\left(a-b k_{12}^{1}-m c_{1}\right)\left(k_{12}^{1}-q_{2}^{0}\right)-\left(a-b k_{12}^{2}-m c\right) k_{12}^{1}
\end{aligned}
$$

For Laspeyres weights, we then see that in each period the capacity of the line chosen by the Transco is lower than the capacity preferred by the ISO $\left(\frac{a-m c_{1}}{b}\right)$ (See Appendix A). In relatively low congested networks $\left(q^{0}>\hat{q}\right)$ the expansion of the network occurs during the first period. In such a case, a further expansion in the next period is too costly compared to the extra profits that the Transco might obtain. From (34) and (35), we observe that the higher the capacities chosen by the Transco, the higher are its fixed charges.

\subsection{Ideal Weights}

The second type of weight analyzed is the ideal weight. An ideal weight $q^{*}$ is the level of $q$ that prevails in the steady state Ramsey-pricing equilibrium (as in Laffont and Tirole, 1996). As suggested in Hogan et al. (2010) and Rosellón and Weigt (2011), the value of $q *$ might be approximated by redefining the lower-level welfare optimization problem in such a way that the ISO chooses the line capacities in the whole transmission grid. That is, the ISO centrally minimizes the costs for expanding the transmission network. In our stylized topology, this solution would look like:

$$
\max _{q_{2}^{t}, k_{12}^{t}} \sum_{t=1}^{2} \int_{0}^{q_{2}^{t}}\left(a-b \tilde{q}_{2}^{t}\right) \mathrm{d} \tilde{q}_{2}^{t}-\sum_{t=1}^{2} m c_{1} q_{2}^{t}-\sum_{t=1}^{2} \operatorname{ecf}\left(k_{12}^{t}-k_{12}^{t-1}\right)
$$


subject to:

$$
\begin{aligned}
q_{2}^{t} & \leq g_{1}^{t, \max } \quad t=1,2 \\
q_{2}^{t} & \leq k_{12}^{t} \quad t=1,2 \\
k_{12}^{1} & \leq k_{12}^{2} .
\end{aligned}
$$

which has solution:

$$
q^{*}=\frac{2\left(a-m c_{1}\right)-e c f}{2 b} .
$$

(Appendix B demonstrates how $q *$ is determined specifically.)

Returning to the regulatory problem defined in 3.2, a solution under ideal weights in the upper level must consider the optimal choices from the lower level. This problem will take the form:

$$
\begin{array}{r}
\max _{k_{12}^{t}}\left(p_{2}^{1}-p_{1}^{1}\right) q_{2}^{1}-\frac{\left(p_{2}^{1}\right)\left(2 a-2 m c_{1}-e c f\right)}{2 b}-e c f k_{12}^{1}+\beta\left(\left(p_{2}^{2}-p_{1}^{2}\right) q_{2}^{2}-\right. \\
\left.-\frac{\left(p_{2}^{2}\right)\left(2 a-2 m c_{1}-e c f\right)}{2 b}-\operatorname{ecf}\left(k_{12}^{2}-k_{12}^{1}\right)\right)+\pi_{0}^{*}
\end{array}
$$

where $\pi_{0}^{*}:=\left(\gamma+\beta \gamma^{2}\right)\left[\left(p_{2}^{0}-p_{1}^{0}\right) q^{*}+F^{0} N\right]+e c f k_{12}^{0}$.

The optimal choices of the Transco are given by:

$$
\begin{gathered}
k_{12}^{1}=k_{12}^{2}=\frac{a-m c_{1}}{b}-\frac{(3+\beta) e c f}{4 b(1+\beta)} \\
F^{1} N=\gamma\left[\left(p_{2}^{0}-p_{1}^{0}\right) q^{*}+F^{0} N\right]-\left(a-b k_{12}^{1}-m c_{1}\right) q^{*} \\
F^{2} N=(\gamma)^{2}\left[\left(p_{2}^{0}-p_{1}^{0}\right) q^{*}+F^{0} N\right]-\left(a-b k_{12}^{2}-m c_{1}\right) q^{*}
\end{gathered}
$$

(Appendix C contains the full solution for these problems.)

In this case, when the expansion costs are small the Transco again chooses line capacities slightly below those that the ISO would prefer. Such capacities do not depend on the initial congestion of the network. Once more, it may be observed that the larger capacities in each period are, the larger the fixed charges will be. The network expansion will take place entirely during the first period. 


\section{Distributive Effects of the HRV Mechanism}

The welfare converging properties of the HRV mechanism have already been demonstrated in the literature, but this comes at the cost of high fixed fees. These fees may pose problems in a real world policy implementation of such an incentive tool. Rosellón and Weigt (2012) and Schill et al. (2011) suggest that price-weight parameters in the regulatory constraint in the upper level of the HRV model might be used to achieve different distributive goals among the various Pareto optimal potential solutions in such a model.

In this section we will separately address the effects on surpluses of economic agents as well as on fixed charges, determined by the regulator's choice of weights. To simplify the analysis, we will assume that for the initial period (period zero) the fixed charges are zero, that the firm is myopic $(\beta=1)$, and that there are no efficiency and inflation adjustments $(\gamma=1)$.

\subsection{Effects on the Transco's Profits}

Transco profits are obtained by substituting the obtained solutions in capacity values into the profit function of the Transco. The Transco's profits for the different types of weights are:

\section{Laspeyres weights:}

$$
\frac{e c f^{2}}{8 b}-\frac{\left(a-m c_{1}-b q_{2}^{0}\right) e c f}{2 b}+\frac{-3 b^{2}\left(q_{2}^{0}\right)^{2}+2 a b q_{2}^{0}-2 b m c_{1} q_{2}^{0}+a^{2}-2 a m c_{1}+\left(m c_{1}\right)^{2}}{2 b}
$$

if $q_{2}^{0}>\hat{q}$, and

$$
\frac{2 e c f^{2}}{7 b}-\frac{5\left(a-m c_{1}-b q_{2}^{0}\right) e c f}{7 b}+\frac{2\left(-5 b^{2}\left(q_{2}^{0}\right)^{2}+3 a b q_{2}^{0}-3 b m c_{1} q_{2}^{0}+2 a^{2}-4 a m c_{1}+2\left(m c_{1}\right)^{2}\right)}{7 b}
$$

if $q_{2}^{0}<\hat{q}$.

\section{Ideal weights:}

$$
\frac{e c f^{2}}{2 b}-\frac{2\left(a-m c_{1}-b q_{2}^{0}\right) e c f}{b}+\frac{2\left(-a b q_{2}^{0}+b m c_{1} q_{2}^{0}+a^{2}-2 a m c_{1}+\left(m c_{1}\right)^{2}\right)}{b}
$$

We now compare these two expressions. If we subtract the profits under ideal weights from profits under Laspeyres weights, we get:

$$
-\frac{3 e c f^{2}}{8 b}+\frac{3\left(a-m c_{1}-b q_{2}^{0}\right) e c f}{2 b}-\frac{3\left(a-m c_{1}-b q_{2}^{0}\right)^{2}}{2 b}
$$


if $q_{0}^{2}>\hat{q}$, and

$$
-\frac{3 e c f^{2}}{14 b}+\frac{9\left(a-m c_{1}-b q_{2}^{0}\right) e c f}{7 b}-\frac{10\left(a-m c_{1}-b q_{2}^{0}\right)^{2}}{7 b}
$$

if $q_{2}^{0}<\hat{q}$.

We observe that (45) can be rewritten as:

$$
-\frac{3\left(2 a-2 m c_{1}-2 b q_{2}^{0}-e c f\right)^{2}}{8 b}
$$

and the last equation (46) as:

$$
-\frac{3 e c f^{2}}{14 b}-\frac{a-m c_{1}-b q_{2}^{0}}{7 b}\left[10\left(a-m c_{1}-b q_{2}^{0}\right)-9 e c f\right]
$$

Additionally, if we remember that $q_{2}^{0}<\hat{q}=\frac{2\left(a-m c_{1}\right)-3 e c f}{2 b}$ for $q_{2}^{0}$ in (46), we have:

$$
a-m c_{1}-b q_{2}^{0}>\frac{3}{2} e c f>e c f .
$$

Thus, these two equations are negative expressions. We can therefore conclude that the Transco obtains higher profits under ideal weights than under Laspeyres weights.

\subsection{The Transco's Fixed Charges}

Fixed charges are obtained when optimal capacities are plugged into regulatory constraints (29) and (30). The sums of the fixed fees that the Transco charges to consumers over the two analyzed periods, for each type of weight, are given by:

\section{Laspeyres Weights}

In this case the weights are:

$$
\left(a-m c_{1}-b q_{2}^{0}\right) q_{2}^{0}
$$

if $q_{2}^{0}>\hat{q}$, and

$$
\frac{3 e c f^{2}}{49 b}-\frac{\left(11 a-11 m c_{1}+24 b q_{2}^{0}\right) e c f}{49 b}+\frac{2\left(a-m c_{1}-b q_{2}^{0}\right)\left(3 a-3 m c_{1}+25 b q_{2}^{0}\right)}{49 b}
$$

if $q_{2}^{0}<\hat{q}$. 


\section{Ideal Weights}

The weights are:

$$
\frac{e c f^{2}}{2 b}-\frac{\left(2 a-2 m c_{1}-b q_{2}^{0}\right) e c f}{b}+\frac{2\left(a-m c_{1}-b q_{2}^{0}\right)\left(a-m c_{1}\right)}{b} .
$$

Subtracting the fixed charges under ideal weights from those under Laspeyres weights, we obtain:

$$
-\frac{\left(a-m c_{1}-b q_{2}^{0}-e c f\right)\left(3 a-3 m c+b q_{2}^{0}-e c f\right)}{4 b}
$$

if $q_{2}^{0}>\hat{q}$, and

$$
-\frac{43 e c f^{2}}{98 b}+\frac{\left(87 a-87 m c_{1}-73 b q_{2}^{0}\right) e c f}{49 b}-\frac{\left(a-m c_{1}-b q_{2}^{0}\right)\left(92 a-92 m c_{1}-50 b q_{2}^{0}\right)}{49 b}
$$

if $q_{2}^{0}<\hat{q}$.

In general, expression (50) may be either positive or negative, but for relatively low values of ecf the expression becomes negative. Regarding (51), it can be shown that this term is negative. We know that the variables in (51) satisfy $q_{2}^{0}<\hat{q}$, so using the logic of the previous solution, we get:

$$
a-m c_{1}-b q_{2}^{0}>e c f
$$

which implies:

$$
\begin{aligned}
& 92\left(a-m c_{1}\right)-50 b q_{2}^{0}>42 b q_{2}^{0} \\
& 87\left(a-m c_{1}\right)-73 b q_{2}^{0}>14 b q_{2}^{0},
\end{aligned}
$$

Subtracting the first inequality from the second, we get:

$$
\left[92\left(a-m c_{1}\right)-50 b q_{2}^{0}\right]-\left[87\left(a-m c_{1}\right)-73 b q_{2}^{0}\right]>28 b q_{2}^{0}>0
$$

then

$$
\left[92\left(a-m c_{1}\right)-50 b q_{2}^{0}\right]>\left[87\left(a-m c_{1}\right)-73 b q_{2}^{0}\right]
$$

Finally, from (52) we have:

$$
\frac{\left(a-m c_{1}-b q_{2}^{0}\right)\left(92 a-92 m c_{1}-50 b q_{2}^{0}\right)}{49 b}>\frac{\left(87 a-87 m c_{1}-73 b q_{2}^{0}\right) e c f}{49 b}
$$


Therefore, we conclude that (51) is negative.

The results in subsection 4.2 then tell us that within a congested network (small $q_{2}^{0}$ ) or with low expansion costs (small ecf), the use of ideal weights will result in higher fixed charges as when Laspeyres weights are used in the regulatory constraint.

\subsection{Consumer Surplus}

From previous developments in above sections, we know that $q_{2}^{t}=k_{2}^{t}$ and $p_{2}^{t}=$ $\left(a-b k_{1}^{t} 2\right)$, with $k_{1}^{t} 2 \leqslant \frac{\left(a-m c^{1}\right)}{b}$.

Therefore total consumer surplus in the two periods is given by:

$$
\begin{aligned}
\sum_{t=1}^{2}\left[\int_{0}^{k_{12}^{t}}(a-b k) \mathrm{d} k-\left(a-b k_{12}^{t}\right) k_{12}^{t}\right] & =\sum_{t=1}^{2}\left[a k_{12}^{t}-b \frac{\left(k_{12}^{t}\right)^{2}}{2}-\left(a-b k_{12}^{t}\right) k_{12}^{t}\right] \\
& =\sum_{t=1}^{2} b \frac{\left(k_{12}^{t}\right)^{2}}{2} \\
& =\frac{b\left(\left(k_{12}^{1}\right)^{2}+\left(k_{12}^{2}\right)^{2}\right)}{2}
\end{aligned}
$$

\section{Laspeyres Weights}

$$
\frac{\left(a-m c_{1}+b q_{2}^{0}\right)^{2}}{4 b}
$$

if $q_{0}^{2}>\hat{q}$, and

$$
\frac{17 e c f^{2}}{98 b}-\frac{\left(23 a-23 m c_{1}+12 b q_{2}^{0}\right) e c f}{49 b}+\frac{17\left(a-m c_{1}\right)^{2}+22 b q_{2}^{0}\left(a-m c_{1}\right)+10 b^{2}\left(q_{2}^{0}\right)^{2}}{49 b}
$$

if $q_{0}^{2}<\hat{q}$.

\section{Ideal Weights}

The surplus is given by:

$$
b\left(\frac{a-m c_{1}}{b}-\frac{e c f}{2 b}\right)^{2}
$$

We now again subtract the consumer surplus under ideal weights from the consumer 
surplus under Laspeyres weights:

$$
-\frac{\left(3 a-3 m c_{1}-e c f+b q_{2}^{0}\right)\left(a-m c_{1}-e c f-b q_{2}^{0}\right)}{4 b}
$$

if $q_{2}^{0}>\hat{q}$, and

$$
-\frac{15 e c f^{2}}{196 b}+\frac{2\left(13 a-13 m c_{1}-6 b q_{2}^{0}\right) e c f}{49 b}-\frac{2\left(a-m c_{1}-b q_{2}^{0}\right)\left(16 a-16 m c_{1}+5 b q_{2}^{0}\right)}{49 b}
$$

if $q^{0}<\hat{q}$.

We can now observe that (54) is negative. For sufficiently low values of ecf, the expression becomes negative. Meanwhile, expression (55) is always negative, since:

$$
16\left(a-m c_{1}\right)+5 b q_{2}^{0}>13\left(a-m c_{1}\right)-6 b q_{2}^{0}
$$

which implies:

$$
\frac{2\left(a-m c_{1}-b q_{2}^{0}\right)\left(16 a-16 m c_{1}+5 b q_{2}^{0}\right)}{49 b}>\frac{2\left(13 a-13 m c_{1}-6 b q_{2}^{0}\right) e c f}{49 b} .
$$

The conclusion in this section is similar to the previous. In a congested network (small $q_{2}^{0}$ ) or with low expansion costs (ecf sufficiently small), the use of ideal weights will result in a larger consumer surplus than under Laspeyres weights.

\subsection{Consumer Utility}

In this subsection we assume that the fixed charges are covered wholly by consumers. The net consumer utility is then defined as the net consumer surplus after paying the fixed charges from the Transco. For each weight, we get: 


\section{Laspeyres Weights}

with utility:

$$
\frac{\left(a-m c_{1}+b q_{2}^{0}\right)^{2}}{4 b}-\left(a-m c_{1}-b q_{2}^{0}\right) q_{2}^{0}
$$

if $q_{0}^{2}>\hat{q}$, and

$$
\frac{11 e c f^{2}}{98 b}-12 \frac{\left(a-m c_{1}-b q_{2}^{0}\right) e c f}{49 b}+\frac{60 b^{2}\left(q_{2}^{0}\right)^{2}-22 b q_{2}^{0}\left(a-m c_{1}\right)+11\left(a-m c_{1}\right)^{2}}{49 b}
$$

if $q_{0}^{2}<\hat{q}$.

\section{Ideal Weights}

with utility:

$$
-\frac{e c f^{2}}{4 b}+\frac{\left(a-m c_{1}-b q_{2}^{0}\right) e c f}{b}-\frac{\left(a-m c_{1}\right)\left(a-m c_{1}-2 b q_{2}^{0}\right)}{b} .
$$

Subtracting the net utility under ideal weights from net utility from Laspeyres weights, we get:

$$
\frac{e c f^{2}}{4 b}-\frac{\left(a-m c_{1}-b q_{2}^{0}\right) e c f}{b}+\frac{5\left(a-m c_{1}-b q_{2}^{0}\right)^{2}}{4 b}
$$

if $q^{0}>\hat{q}$, and

$$
\frac{71 e c f^{2}}{196 b}-\frac{61\left(a-m c_{1}-b q_{2}^{0}\right) e c f}{49 b}+\frac{60\left(a-m c_{1}-b q_{2}^{0}\right)^{2}}{49 b}
$$

if $q^{0}<\hat{q}$.

Expression (56) can be rewritten as:

$$
\frac{1}{4 b}\left[\left(e c f-2\left(a-m c-b q_{2}^{0}\right)\right)^{2}+\left(a-m c_{1}-b q_{2}^{0}\right)^{2}\right],
$$

and (57) as

$$
\frac{71}{196 b}\left[e c f-\frac{122}{71}\left(a-m c_{1}-b q_{2}^{0}\right)\right]^{2}+\frac{11}{71 b}\left(a-m c_{1}-b q_{2}^{0}\right)^{2} .
$$

Both expressions are positive. Therefore when consumers have to cover the Transco's fixed charges, net utility is greater under Laspeyres weights than under ideal weights. 


\subsection{Numerical Example}

For our stylized network containing two nodes, one generating sufficient power but the second lacking, we consider the following:

- For simplicity, marginal costs are equal to zero.

- Node 2 has a demand function of the form: $p\left(d_{2}\right)=10-d_{2}$.

- The locational price at node 1 is at the marginal-cost level, and the locational price of node 2 includes congestion charges due to lack of domestic generation capacity.

- The initial capacity of line $k_{12}^{0}$ and net initial injections $q_{2}^{0}$ are equal to $5 \mathrm{MW}$.

- The expansion costs for the Transco are given ky $k_{12}^{t}-k_{12}^{t-1}$.

- The inflation and efficiency factors are ignored in the regulatory constraint (i.e., $\mathrm{RPI}=0$, and $\mathrm{X}=0$ )

- The Transco is in principle myopic, attributing equal weights to profits in each period.

Taking these assumptions into consideration in conjunction with different values for $\beta$ and $\gamma$ we obtain values for fixed charges, consumer surplus, net consumer utility, and the Transco's profits. These are summarized in the following tables, where W.L. denotes the values obtained for Laspeyres weights, and W.I denotes those values corresponding to ideal weights:

Fixed Charges

\begin{tabular}{|c|c|c|c|}
\hline & \multicolumn{3}{|c|}{$\beta$} \\
\hline & 1 & 0.9 & 0.8 \\
\hline \multirow{2}{*}{1.1} & W.L. 35.5549 & W.L. 35.5433 & W.L. 35.5306 \\
\hline & W.I. 100.2250 & W.I. 99.9750 & W.I. 99.6972 \\
\hline \multirow{2}{*}{1} & W.L. 27.0000 & W.L. 27.0000 & W.L.27.0000 \\
\hline & W.I. 85.5000 & W.I. 85.2500 & P. I. 84.9722 \\
\hline \multirow{2}{*}{0.9} & W.L. 18.9253 & W.L. 18.9395 & W.L. 18.9549 \\
\hline & W.I. 71.7250 & W.I. 71.4750 & W.I. 71.1972 \\
\hline
\end{tabular}




\section{Consumer Surplus}

\begin{tabular}{|c|c|c|c|}
\multicolumn{1}{c}{} & \multicolumn{3}{c|}{$\beta$} \\
\cline { 2 - 4 } \multicolumn{1}{c|}{} & 1 & 0.9 & 0.8 \\
\hline \multirow{2}{*}{1.1} & W.L. 56.7977 & W.L. 56.7808 & W.L. 56.7622 \\
\cline { 2 - 4 } & W.I. 90.2500 & W.I. 90.0001 & W.I. 89.7229 \\
\hline \multirow{2}{*}{1} & W.L. 56.5000 & W.L. 56.5000 & W.L. 56.5000 \\
\cline { 2 - 4 } & W.I. 90.2500 & W.I. 90.0001 & W.I. 89.7229 \\
\hline \multirow{2}{*}{0.9} & W.L. 56.1672 & W.L. 56.1882 & W.L. 56.2109 \\
\cline { 2 - 4 } & W.I. 90.2500 & W.I. 90.0001 & W.I. 89.7229 \\
\hline
\end{tabular}

Consumer Surplus - Fixed Charges

\begin{tabular}{|c|c|c|c|}
\multicolumn{4}{c}{} \\
\cline { 2 - 4 } \multicolumn{1}{c|}{} & 1 & 0.9 & 0.8 \\
\hline \multirow{2}{*}{1.1} & W.L. 21.2427 & W.L. 21.2374 & W.L. 21.2310 \\
\cline { 2 - 4 } & W.I. -9.9750 & W.I. -9.9748 & W.I. -9.9742 \\
\hline \multirow{2}{*}{1} & W.L. 29.5000 & W.L. 29.5000 & W.L. 29.5000 \\
\cline { 2 - 4 } & W.I. 4.7500 & W.I. 4.7501 & W.I. 4.7507 \\
\hline \multirow{2}{*}{0.9} & W.L. 37.2418 & W.L. 37.2486 & W.L. 37.2559 \\
\cline { 2 - 4 } & W.I. 18.5250 & W.I. 18.5251 & W.I. 18.5257 \\
\hline
\end{tabular}

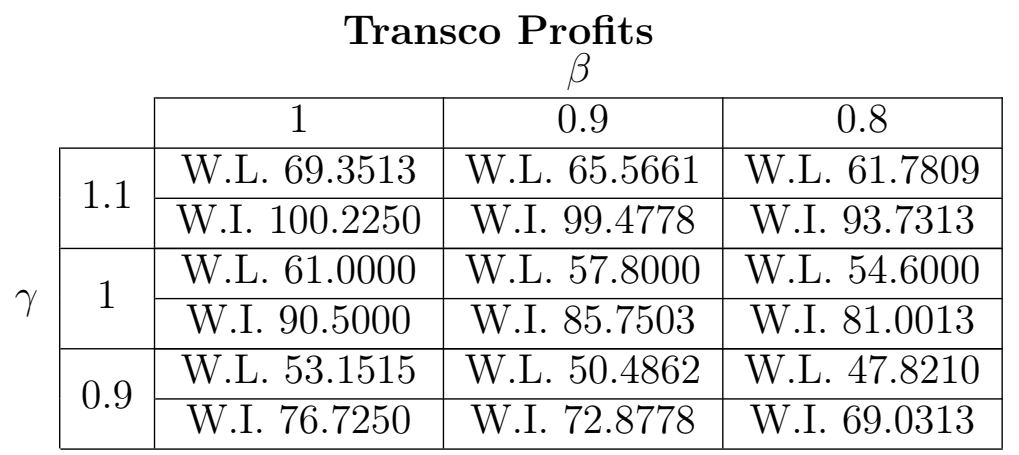

It can be observed that for different combinations of $\beta$ and $\gamma$, there will result higher fixed charges, higher consumer surplus and higher Transco profits for ideal weights than for Laspeyres weights. However, when consumers are obligated to pay the entire fixed charge, Laspeyres weights provide a higher consumer net utility than ideal weights. The values found for this example show little sensitivity to variations in the discount factor $\beta$. However, changes in the efficiency and inflation factors as represented by $\gamma$ have more significant effects over fixed charges as well as the particular surpluses. 


\section{Conclusion}

In this paper we analyzed the distributive effects resulting from the choice of weights under the HRV mechanism for network expansion. In this model, a regulated Transco intertemporally maximizes its profits in a wholesale, perfectly competitive electricity generation market with locational marginal price FTR auctions.

With the use of certain quantity weights, a regulatory agency establishes a maximum price for the two-part tariff covered by the Transco. These regulatory restrictions allow for a rebalancing of the fixed and variable parts of the tariff in order that the Transco preserve its own optimum when congestion rents decrease commensurate to the increase in transmission line capacity. This model also considers the actions of an independent operator (ISO) who coordinates generation and transmission with the goal of maximizing social welfare. The purpose of this mechanism is to increase capacity over congested transmission lines, allowing the transfer of energy from low cost generation zones to high demand zones with elevated generation costs.

The HRV model has been widely studied in the literature. The conclusion has been reached that the model is appropriate from a theoretical and empirical standpoint and it has been applied to many geographical zones. However, its distributive efficiency has been seldom studied and the parameters that affect this are not known. In the context of this work, the welfare of market participants in a radial network and two time periods was studied in order to determine the efficiency of Laspeyres or ideal weights.

As a solution to the lower level problem, it was observed that for both weight types, the capacities of the single lines chosen by the Transco would be insufficient to reach the maximum level of social welfare desired by the ISO. For the higher level problem, a comparison between distinct expressions is exceedingly complex due to the sophisticated interaction of parameters and variables. However, assuming that the Transco equally values profits from both periods and is prescient of changes in inflation and efficiency (just as in the majority of studies and applications cited), one finds that profits for the Transco are always higher when they choose ideal weights than when they choose Laspeyres weights. If the network is not congested or the cost of expansion is sufficiently low, using ideal weights will obtain higher consumer surpluses and larger fixed costs than using Laspeyres weights. Even though the latter result does not appear conclusive, when the fixed charges are passed entirely to consumers, their utility is always higher when choosing Laspeyres weights than using ideal weights, without taking into account the magnitude of expansion costs or congestion level in a given line. In conclusion, it can therefore be said that if a regulator

aims to favor the Transco she should use ideal weights. However, if the regulator is more interested in favoring consumers she should choose Laspeyres weights. 


\section{Appendices}

\subsection{Solution to Upper Level Problem: Laspeyres Weights}

The first type of weight used in this work was the Laspeyres weight, given by $q^{w}=q^{t-1}$. From expressions (13) and (17) we can derive the problem of the Transco:

$$
\max _{k_{12}^{1}, k_{12}^{2}} \beta\left(p_{2}^{2}-p_{1}^{2}\right)\left(q_{2}^{2}-q_{2}^{1}\right)+(1+\beta \gamma)\left(p_{2}^{1}-p_{1}^{1}\right)\left(q_{2}^{1}-q_{2}^{0}\right)-\beta e c f k_{12}^{2}-(1-\beta) \text { ecf } k_{12}^{1}+\pi_{0}
$$

where $\pi_{0}:=\left(\gamma+\beta \gamma^{2}\right)\left[\left(p_{2}^{0}-p_{1}^{0}\right) q_{2}^{0}+F^{0} N\right]+e c f k_{12}^{0}$.

To solve this problem we replace the results that we found through solving the lower level problem. We consider the following cases.

Case 1. Suppose that $k_{12}^{1}, k_{12}^{2} \leq \frac{a-m c_{1}}{b}$. Then

$$
\begin{array}{lll}
q_{2}^{1}=k_{12}^{1}, & p_{2}^{1}=a-b k_{12}^{1}, & p_{1}^{1}=m c, \\
q_{2}^{2}=k_{12}^{2}, & p_{2}^{2}=a-b k_{12}^{2}, & p_{1}^{2}=m c .
\end{array}
$$

Therefore the objective function takes the form:

$$
\pi_{0}-b \beta k_{12}^{2}\left(k_{12}^{2}-k_{12}^{1}\right)-b(1+\beta \gamma) k_{12}^{1}\left(k_{12}^{1}-q_{2}^{0}\right)-\beta e c f k_{12}^{2}-(1-\beta) e c f k_{12}^{1}
$$

subject to $k_{12}^{2}-k_{12}^{1} \geq 0$. If we associate the multiplier $\lambda$ to the last constraint, we get the following Karush Khun Tucker conditions:

$$
\begin{aligned}
k_{12}^{1}: & -2 b k_{12}^{1}+a-m c_{1}+b q_{2}^{0}-e c f+\beta\left(-\gamma b\left(k_{12}^{1}-q_{2}^{0}\right)+\gamma\left(a-m c_{1}-b k_{12}^{1}\right)-a+\right. \\
& \left.+m c+b k_{12}^{2}+e c f\right)-\lambda=0 \\
k_{12}^{2}: \quad & \beta\left(-2 b k_{12}^{2}+a-m c_{1}+b k_{12}^{1}-e c f\right)+\lambda=0 \\
& \lambda\left(k_{12}^{2}-k_{12}^{1}\right)=0
\end{aligned}
$$

Subcase 1.1 Let $\lambda>0, k_{12}^{2}=k_{12}^{1}$. From these conditions we obtain the system:

$$
\begin{aligned}
& -2 b k_{12}^{1}+a-m c_{1}+b q_{2}^{0}-e c f+\beta\left(-\gamma b\left(k_{12}^{1}-q_{2}^{0}\right)+\gamma\left(a-m c_{1}-b k_{12}^{1}\right)-a+\right. \\
& \left.\quad+m c+b k_{12}^{1}+e c f\right)-\lambda=0 \\
& \beta\left(-b k_{12}^{1}+a-m c_{1}-e c f\right)+\lambda=0
\end{aligned}
$$


which when solved gives:

$$
\begin{gathered}
k_{12}^{1}=k_{12}^{2}=\frac{\left(a-m c_{1}+b q_{2}^{0}\right)(1+\beta \gamma)-e c f}{2 b(1+\beta \gamma)} \\
\lambda=-\beta \frac{\left(a-m c_{1}-b q_{2}^{0}-e c f\right)(1+\beta \gamma)-e c f \beta \gamma}{2(1+\beta \gamma)}
\end{gathered}
$$

It can be seen that $\lambda>0$ if and only if:

$$
q_{2}^{0}>\frac{\left(a-m c_{1}\right)(1+\beta \gamma)-e c f(1+2 \beta \gamma)}{b(1+\beta \gamma)}
$$

Subcase 1.2 Now, take $\lambda=0, k_{12}^{2}>k_{12}^{1}$. In this subcase we jointly solve:

$$
\begin{aligned}
& -2 b k_{12}^{1}+a-m c_{1}+b q_{2}^{0}-e c f+\beta\left(-\gamma b\left(k_{12}^{1}-q_{2}^{0}\right)+\gamma\left(a-m c_{1}-b k_{12}^{1}\right)-a+\right. \\
& \left.\quad+m c+b k_{12}^{2}+e c f\right)=0 \\
& \beta\left(-2 b k_{12}^{2}+a-m c_{1}+b k_{12}^{1}-e c f\right)=0
\end{aligned}
$$

so we found that:

$$
\begin{gathered}
k_{12}^{1}=\frac{2\left(a-m c_{1}+b q_{2}^{0}\right) \beta \gamma-(a-m c-e c f) \beta+2\left(a-m c+b q_{2}^{0}-e c f\right)}{b(4-\beta+4 \beta \gamma)} \\
k_{12}^{2}=\frac{\left(3 a-3 m c+b q_{2}^{0}-2 e c f\right) \beta \gamma-(a-m c-e c f) \beta+3 a-3 m c+b q_{0}^{2}-3 e c f}{b(4-\beta+4 \beta \gamma)}
\end{gathered}
$$

Then

$$
k_{12}^{2}-k_{12}^{1}=\frac{\left(b q_{2}^{0}-a+m c+2 e c f\right) \beta \gamma+b q_{2}^{0}-a+m c+e c f}{b(4-\beta+4 \beta \gamma)}
$$

The last expression is positive if and only if:

$$
q_{2}^{0}<\frac{\left(a-m c_{1}\right)(1+\beta \gamma)-e c f(1+2 \beta \gamma)}{b(1+\beta \gamma)}
$$

As a consequence of what we have found so far, in this first case the resulting capacities in the transmission line, as well as the surplus of participants and fixed charges, will depend on the magnitude of $q_{2}^{0}$.

The benefit to the Transco for this first case would then be:

$$
\pi=\pi_{0}+\frac{e c f^{2}}{4 b(1+\beta \gamma)}-\frac{\left(a-m c_{1}+b q_{2}^{0}\right) e c f}{2 b}+\frac{\left(a-m c_{1}-b q_{2}^{0}\right)^{2}(1+\beta \gamma)}{4 b}
$$




$$
\begin{aligned}
\text { if } q_{2}^{0}> & \frac{\left(a-m c_{1}\right)(1+\beta \gamma)-e c f(1+2 \beta \gamma)}{b(1+\beta \gamma)}, \text { or } \\
\pi= & \pi_{0}+\frac{\left(1+\beta^{2} \gamma\right) e c f^{2}}{b(4+4 \beta \gamma-\beta)}-\frac{\left[(a-m c)\left(2+2 \beta \gamma+\beta^{2} \gamma\right)+b(2-\beta)(1+\beta \gamma) q_{2}^{0}\right] e c f}{b(4+4 \beta \gamma-\beta)} \\
& +\frac{\left(a-m c_{1}-b q_{2}^{0}\right)^{2}(1+\beta \gamma)^{2}}{b(4+4 \beta \gamma-\beta)} \\
\text { if } q_{2}^{0}< & \frac{\left(a-m c_{1}\right)(1+\beta \gamma)-e c f(1+2 \beta \gamma)}{b(1+\beta \gamma)} .
\end{aligned}
$$

Case 2. Suppose that $k_{12}^{1} \leq \frac{a-m c_{1}}{b}, k_{12}^{2} \geq \frac{a-m c_{1}}{b}$. Then

$$
\begin{array}{lrr}
q_{2}^{1}=k_{12}^{1}, & p_{2}^{1}=a-b k_{12}^{1}, & p_{1}^{1}=m c_{1} \\
q_{2}^{2}=\frac{a-m c_{1}}{b}, & p_{2}^{2}=m c_{1}, & p_{1}^{2}=m c_{1} .
\end{array}
$$

The objective function of the upper level problem is

$$
\left(a-b k_{12}^{1}-m c_{1}\right) k_{12}^{1}-\left(a-b k_{12}^{1}-m c\right) q_{2}^{0}-e c f k_{12}^{1}+\beta\left(\gamma\left(a-b k_{12}^{1}-m c_{1}\right)\left(k_{12}^{1}-q_{2}^{0}\right)-e c f\left(k_{12}^{2}-k_{12}^{1}\right)\right)+\pi_{0}
$$

Since this function is linear in $k_{12}^{2}$ with a negative coefficient, we take

$$
k_{12}^{2}=\frac{a-m c_{1}}{b} .
$$

The first order condition for $k_{12}^{1}$ is:

$k_{12}^{1}: \quad-2 b k_{12}^{1}+a-m c_{1}+b q_{2}^{0}-e c f+\beta\left(-\gamma b\left(k_{12}^{1}-q_{2}^{0}\right)+\gamma\left(a-b k_{12}^{1}-m c\right)+e c f\right)=0$

which implies:

$$
k_{12}^{1}=\frac{\left(a-m c_{1}+b q_{2}^{0}\right)(1+\beta \gamma)-e c f(1-\beta)}{2 b(1+\beta \gamma)}
$$

Substituting into the objective function the capacities previously found, the benefits to the Transco in this case are:

$$
\begin{aligned}
\pi= & \pi_{0}+\frac{(1-\beta)^{2} e c f^{2}}{4 b(1+\beta \gamma)}-\frac{\left[(a-m c)(1+\beta)+b(1-\beta) q_{2}^{0}\right] e c f}{2 b}+ \\
& +\frac{\left(a-m c-b q_{2}^{0}\right)^{2}(1+\beta \gamma)}{4 b}
\end{aligned}
$$


Case 3. Finally, let $k_{12}^{1}, k_{12}^{2} \geq \frac{a-m c_{1}}{b}$. Then

$$
\begin{array}{llrl}
q_{2}^{1}=\frac{a-m c_{1}}{b}, & p_{2}^{1}=m c_{1}, & p_{1}^{1}=a, \\
q_{2}^{2}=\frac{a-m c_{1}}{b}, & p_{2}^{2}=m c_{1}, & p_{1}^{2}=a .
\end{array}
$$

In this case we maximize the expression

$$
-\operatorname{ecf} k_{12}^{1}-\beta e c f\left(k_{12}^{2}-k_{12}^{1}\right)+\pi_{0}
$$

which can be rewritten as $-e c f(1-\beta) k_{12}^{1}-e c f \beta k_{12}^{2}+\pi_{0}$. Since this is linear in $k_{12}^{1}$ y $k_{12}^{2}$, we choose

$$
k_{12}^{1}=k_{12}^{2}=\frac{a-m c_{1}}{b}
$$

Then the benefits of the Transco are

$$
\pi=\pi_{0}-\frac{e c f\left(a-m c_{1}\right)}{b}
$$

\section{Ultimate Solution}

This solution is chosen among three different analyzed cases. The solution will be the case that yields higher benefits for the Transco. Then, we compare our results summarized in equations (67), (68), (73) and (76).

First compare the results for cases 2 and 3. From (73) we have that benefits for case 2 are:

$$
\begin{aligned}
\pi= & \pi_{0}+\frac{(1-\beta)^{2} e c f^{2}}{4 b(1+\beta \gamma)}-\frac{\left[\left(a-m c_{1}\right)(1+\beta)+b(1-\beta) q_{2}^{0}\right] e c f}{2 b}+ \\
& +\frac{\left(a-m c_{1}-b q_{2}^{0}\right)^{2}(1+\beta \gamma)}{4 b} \\
= & \pi_{0}+\frac{(1-\beta)^{2} e c f^{2}}{4 b(1+\beta \gamma)}+\frac{(1-\beta)\left(a-m c_{1}-b q_{2}^{0}\right) e c f}{2 b}+ \\
& +\frac{\left(a-m c_{1}-b q_{2}^{0}\right)^{2}(1+\beta \gamma)}{4 b}-\frac{\left(a-m c_{1}\right) e c f}{b} \\
= & \pi_{0}+\frac{\left[(1-\beta) e c f+\left(a-m c_{1}-b q_{2}^{0}\right)(1+\beta \gamma)\right]^{2}}{4 b(1+\beta \gamma)}-\frac{\left(a-m c_{1}\right) e c f}{b}
\end{aligned}
$$


From (76), by choosing capacities according to case 3 , the Transco receives

$$
\pi=\pi_{0}-\frac{\left(a-m c_{1}\right) e c f}{b}
$$

Clearly, the Trasco always prefers alternative 2 to 3 . Now we compare alternatives 1 and 2 in terms of capacities.

First, assume $q_{2}^{0}>\frac{\left(a-m c_{1}\right)(1+\beta \gamma)-e c f(1+2 \beta \gamma)}{b(1+\beta \gamma)}$.

Now subtract the profits in case 1 given by (67) to the profits in case 2 expressed $\operatorname{in}(73)$ :

$$
\begin{aligned}
& {\left[\pi_{0}+\frac{(1-\beta)^{2} e c f^{2}}{4 b(1+\beta \gamma)}-\frac{\left[\left(a-m c_{1}\right)(1+\beta)+b(1-\beta) q_{2}^{0}\right] e c f}{2 b}+\frac{\left(a-m c_{1}-b q_{2}^{0}\right)^{2}(1+\beta \gamma)}{4 b}\right]-} \\
& {\left[\pi_{0}+\frac{e c f^{2}}{4 b(1+\beta \gamma)}-\frac{\left(a-m c_{1}+b q_{2}^{0}\right) e c f}{2 b}+\frac{\left(a-m c_{1}-b q_{2}^{0}\right)^{2}(1+\beta \gamma)}{4 b}\right]=} \\
& -\frac{\beta(2-\beta) e c f^{2}}{4 b(1+\beta \gamma)}-\frac{\left(a-m c-b q_{2}^{0}\right) \beta e c f}{2 b}<0 .
\end{aligned}
$$

It follows that option 1 is preferred to option 2 .

Now, let $q_{2}^{0}<\frac{\left(a-m c_{1}\right)(1+\beta \gamma)-e c f(1+2 \beta \gamma)}{b(1+\beta \gamma)}$.

Again, subtract the profits in case 1 given by (68) to profits in case 2 expressed in 
equation (73):

$$
\begin{aligned}
& {\left[\pi_{0}+\frac{(1-\beta)^{2} e c f^{2}}{4 b(1+\beta \gamma)}-\frac{\left[\left(a-m c_{1}\right)(1+\beta)+b(1-\beta) q_{2}^{0}\right] e c f}{2 b}+\frac{\left(a-m c_{1}-b q_{2}^{0}\right)^{2}(1+\beta \gamma)}{4 b}\right]-} \\
& {\left[\pi_{0}+\frac{\left(1+\beta^{2} \gamma\right) e c f^{2}}{b(4+4 \beta \gamma-\beta)}-\frac{\left[(a-m c)\left(2+2 \beta \gamma+\beta^{2} \gamma\right)+b(2-\beta)(1+\beta \gamma) q_{2}^{0}\right] e c f}{b(4+4 \beta \gamma-\beta)}+\right.} \\
& \left.+\frac{\left(a-m c_{1}-b q_{2}^{0}\right)^{2}(1+\beta \gamma)^{2}}{b(4+4 \beta \gamma-\beta)}\right]= \\
& -\frac{\beta(2 \beta \gamma-\beta+3)^{2} e c f^{2}}{4 b(4+4 \beta \gamma-\beta)}-\frac{\beta\left(a-m c_{1}-b q_{2}^{0}\right)(2 \beta \gamma-\beta+3) e c f}{2 b(4+4 \beta \gamma-\beta)}- \\
& \frac{\beta\left(a-m c_{1}-b q_{2}^{0}\right)^{2}(1+\beta \gamma)}{4 b(4+4 \beta \gamma-b e t a)}= \\
& \beta\left[(2 \beta \gamma-\beta+3) e c f+\left(a-m c_{1}-b q_{2}^{0}\right)(1+\beta \gamma)\right]^{2} \\
& -\frac{\beta b(4+\beta \gamma-\beta)(1+\beta \gamma)}{\beta(1+\beta \gamma} .
\end{aligned}
$$

Then, the Transco always chooses option 1 over option 2. In conclusion, optimally chosen capacities in the upper level problem are given by:

$$
\begin{aligned}
& k_{12}^{1}=\left\{\begin{array}{cc}
\frac{\left(a-m c_{1}+b q_{2}^{0}\right)(1+\beta \gamma)-e c f}{2 b(1+\beta \gamma)} & \text { if } q_{2}^{0}>\hat{q} \\
\frac{2\left(a-m c_{1}+b q_{2}^{0}\right) \beta \gamma-(a-m c-e c f) \beta+2\left(a-m c+b q_{2}^{0}-e c f\right)}{b(4-\beta+4 \beta \gamma)} & \text { in other case }
\end{array}\right. \\
& k_{12}^{2}= \begin{cases}\frac{\left(a-m c_{1}+b q_{2}^{0}\right)(1+\beta \gamma)-e c f}{2 b(1+\beta \gamma)} & \text { if } q_{2}^{0}>\hat{q} \\
\frac{\left(3 a-3 m c+b q_{2}^{0}-2 e c f\right) \beta \gamma-(a-m c-e c f) \beta+3 a-3 m c+b q_{0}^{2}-3 e c f}{b(4-\beta+4 \beta \gamma)} & \text { in other case }\end{cases}
\end{aligned}
$$

where $\hat{q}=\frac{\left(a-m c_{1}\right)(1+\beta \gamma)-e c f(1+2 \beta \gamma)}{b(1+\beta \gamma)}$.

With fixed charges accordingly defined as:

$$
\begin{aligned}
& F^{1} N=\gamma\left[\left(p_{2}^{0}-p_{1}^{0}\right) q_{2}^{0}+F^{0} N\right]-\left(a-b k_{12}^{1}-m c_{1}\right) q_{2}^{0} \\
& F^{2} N=(\gamma)^{2}\left[\left(p_{2}^{0}-p_{1}^{0}\right) q_{1}^{0}+F^{0} N\right]+\gamma\left(a-b k_{12}^{1}-m c_{1}\right)\left(k_{12}^{1}-q_{2}^{0}\right)-\left(a-b k_{12}^{2}-m c\right) k_{12}^{1}
\end{aligned}
$$




\subsection{Finding the Ideal Weight}

In order to find the ideal weight for our two-period radial network, we must solve the problem

$$
\max _{q_{2}^{t}, k_{12}^{t}} \sum_{t=1}^{2} \int_{0}^{q_{2}^{t}}\left(a-b \tilde{q}_{2}^{t}\right) \mathrm{d} \tilde{q}_{2}^{t}-\sum_{t=1}^{2} m c_{1} q_{2}^{t}-\sum_{t=1}^{2} \operatorname{ecf}\left(k_{12}^{t}-k_{12}^{t-1}\right)
$$

subject to:

$$
\begin{aligned}
q_{2}^{t} & \leq g_{1}^{t, \max } \quad t=1,2 \\
q_{2}^{t} & \leq k_{12}^{t} \quad t=1,2 \\
k_{12}^{1} & \leq k_{12}^{2} .
\end{aligned}
$$

To avoid wasting resources, it must be true that $q_{2}^{t}=k_{12}^{t}$. Then, assuming sufficient generating capacity at node 1 , the problem is rewritten as:

$$
\max _{q_{2}^{t}, k_{12}^{t}} \sum_{t=1}^{2} \int_{0}^{q_{2}^{t}}\left(a-b \tilde{q}_{2}^{t}\right) \mathrm{d} \tilde{q}_{2}^{t}-\sum_{t=1}^{2}\left(m c_{1}+e c f\right) q_{2}^{t}+\sum_{t=1}^{2} e c f q_{2}^{t-1}
$$

subject to

$$
q_{2}^{1} \leq q_{2}^{2}
$$

If we associate the multiplier $\mu$ to the latter restrictions, the KKT conditions of the problem are:

$$
\begin{array}{ll}
q_{2}^{1}: & a-b q_{2}^{1}-\left(m c_{1}+e c f\right)+e c f-\mu=0 \\
q_{2}^{2}: & a-b q_{2}^{2}-\left(m c_{1}+e c f\right)+\mu=0 \\
& \mu\left(q_{2}^{2}-q_{2}^{1}\right)=0 .
\end{array}
$$

First, suppose that $\mu>0 ; q_{2}^{1}=q_{2}^{2}$.

We obtain the system:

$$
\begin{array}{r}
a-b q_{2}^{1}-m c_{1}-\mu=0 \\
a-b q_{2}^{1}-m c_{1}-e c f+\mu=0
\end{array}
$$

then

$$
\begin{aligned}
q_{2}^{1}=q_{2}^{1} & =\frac{2\left(a-m c_{1}\right)-e c f}{2 b} \\
\mu & =\frac{e c f}{2}>0
\end{aligned}
$$


Now consider the case $\mu=0 ; q_{2}^{1}<q_{2}^{2}$.

Now the system to be solved is:

$$
\begin{array}{r}
a-b q_{2}^{1}-m c_{1}=0 \\
a-b q_{2}^{2}-m c_{1}-e c f=0
\end{array}
$$

solving this system yields:

$$
\begin{gathered}
q_{2}^{1}=\frac{a-m c_{1}}{b} \\
q_{2}^{2}=\frac{a-m c_{1}-e c f}{b}
\end{gathered}
$$

but

$$
q_{2}^{2}-q_{1}^{1}=-\frac{e c f}{b}<0
$$

so that we may discard this second case.

In conclusion, the ideal weight is then given by

$$
q^{*}=\frac{2\left(a-m c_{1}\right)-e c f}{2 b} .
$$

\subsection{Solution to the Upper Level Problem: Ideal Weights}

The second type of weight that we consider in this paper are ideal weights. An ideal weight $q^{*}$ is the level of $q$ that prevails in the steady (Ramsey-Boiteux) state. In

our network we found that the ideal weight is given by $q^{*}=\frac{2\left(a-m c_{1}\right)-e c f}{2 b}$. In order to solve the upper level problem for this type of weight we will again consider various cases given the variety of choices in the lower level problem. The problem to be solved:

$$
\begin{array}{r}
\max _{k_{12}^{t}}\left(p_{2}^{1}-p_{1}^{1}\right) q_{2}^{1}-\frac{\left(p_{2}^{1}\right)\left(2 a-2 m c_{1}-e c f\right)}{2 b}-e c f k_{12}^{1}+\beta\left(\left(p_{2}^{2}-p_{1}^{2}\right) q_{2}^{2}-\right. \\
\left.-\frac{\left(p_{2}^{2}\right)\left(2 a-2 m c_{1}-e c f\right)}{2 b}-\operatorname{ecf}\left(k_{12}^{2}-k_{12}^{1}\right)\right)+\pi_{0}^{*}
\end{array}
$$

where $\pi_{0}^{*}:=\left(\gamma+\beta \gamma^{2}\right)\left[\left(p_{2}^{0}-p_{1}^{0}\right) q^{*}+F^{0} N\right]+e c f k_{12}^{0}$. 
Case 1. Suppose that the Transco chooses $k_{12}^{1}, k_{12}^{2} \leq \frac{a-m c_{1}}{b}$. As before, we have that

$$
\begin{array}{ccc}
q_{2}^{1}=k_{12}^{1}, & p_{2}^{1}=a-b k_{12}^{1}, & p_{1}^{1}=m c \\
q_{2}^{2}=k_{12}^{2}, & p_{2}^{2}=a-b k_{12}^{2}, & p_{1}^{2}=m c .
\end{array}
$$

The objective function is now given by:

$$
\begin{aligned}
& \left(a-b k_{12}^{1}\right) k_{12}^{1}-\frac{\left(a-b k_{12}^{1}-m c_{1}\right)(2 a-2 m-e c f)}{2 b}-e c f k_{12}^{1}+\beta\left(\left(a-b k_{12}^{2}-m c_{1}\right) k_{12}^{2}-\right. \\
& \left.\frac{\left(a-b k_{12}^{2}-m c_{1}\right)(2 a-2 m-e c f)}{2 b}-e c f\left(k_{12}^{2}-k_{12}^{1}\right)\right)+\pi_{0}^{*}
\end{aligned}
$$

The Karush-Khun-Tucker conditions for this problem are:

$$
\begin{array}{ll}
k_{12}^{1}: \quad & -2 b k_{12}^{1}+2 a-2 m c_{1}-\frac{3 e c f}{2}+\beta e c f-\lambda=0 \\
k_{12}^{2}: \quad & \beta\left(-2 b k_{12}^{2}+2 a-2 m c-\frac{3 e c f}{2}\right)+\lambda=0 \\
& \lambda\left(k_{12}^{2}-k_{12}^{1}\right)=0
\end{array}
$$

Subcase 1.1. Let $\lambda>0 ; k_{12}^{1}=k_{12}^{2}$, from the first order conditions we get:

$$
\begin{array}{r}
-2 b k_{12}^{1}+2 a-2 m c_{1}-\frac{3 e c f}{2}+\beta e c f-\lambda=0 \\
\beta\left(-2 b k_{12}^{1}+2 a-2 m c-\frac{3 e c f}{2}\right)+\lambda=0
\end{array}
$$

whose solution is:

$$
\begin{gathered}
k_{12}^{1}=k_{12}^{2}=\frac{a-m c_{1}}{b}-\frac{(3+\beta) e c f}{4 b(1+\beta)} \\
\lambda=\frac{e c f \beta^{2}}{1+\beta}
\end{gathered}
$$

Subcase 1.2 Assume $\lambda=0 ; k_{12}^{2}>k_{12}^{1}$. We get the equations:

$$
\begin{array}{ll}
k_{12}^{1}: & -2 b k_{12}^{1}+2 a-2 m c_{1}-\frac{3 e c f}{2}+\beta e c f=0 \\
k_{12}^{2}: & \beta\left(-2 b k_{12}^{2}+2 a-2 m c-\frac{3 e c f}{2}\right)=0
\end{array}
$$


therefore

$$
\begin{aligned}
& k_{12}^{1}=\frac{a-m c_{1}}{b}-\frac{(3-2 \beta) e c f}{4 b} \\
& k_{12}^{2}=\frac{a-m c_{1}}{b}-\frac{3 e c f}{4 b},
\end{aligned}
$$

so that

$$
k_{12}^{2}-k_{12}^{1}=-\frac{\beta e c f}{2 b}<0
$$

so that we may discard this first case..

The profits for the Transco in this case are given by:

$$
\pi=\pi_{0}^{*}+\frac{(3+\beta)^{2} e c f^{2}}{16 b(1+\beta)}-\frac{e c f(a-m c)}{b}
$$

Case 2. Now, let's see what happens when the Transco chooses $k_{12}^{1} \leq \frac{a-m c}{b}$ and $k_{12}^{1} \geq \frac{a-m c}{b}$. We get

$$
\begin{array}{lrr}
q_{2}^{1}=k_{12}^{1}, & p_{2}^{1}=a-b k_{12}^{1}, & p_{1}^{1}=m c_{1} \\
q_{2}^{2}=\frac{a-m c_{1}}{b}, & p_{2}^{2}=m c_{1}, & p_{1}^{2}=m c_{1} .
\end{array}
$$

The objective function of the upper level problem is

$$
\left(a-b k_{12}^{1}-m c_{1}\right) k_{12}^{1}-\frac{\left(a-b k_{12}^{1}-m c_{1}\right)\left(2 a-2 m c_{1}-e c f\right)}{2 b}-\operatorname{ecf} k_{12}^{1}-\beta e c f\left(k_{12}^{2}-k_{12}^{1}\right)+\pi_{0}^{*}
$$

As this function is linear in $k_{12}^{2}$, we choose

$$
k_{12}^{2}=\frac{a-m c_{1}}{b}
$$

For $k_{12}^{1}$, we have the first order condition:

$$
k_{12}^{1}: \quad-2 b k_{12}^{1}+2 a-2 m c_{1}-\frac{3 e c f}{2}+\beta e c f=0
$$

Then

$$
k_{12}^{1}=\frac{a-m c_{1}}{b}-\frac{(3-2 \beta) e c f}{4 b}
$$


substituting these values for $k_{12}^{1}$ and $k_{12}^{2}$ in the objective function, we find that the profits obtained by the Transco are given by:

$$
\pi=\pi_{0}^{*}+\frac{(3-2 \beta)^{2} e c f^{2}}{16 b}-\frac{e c f\left(a-m c_{1}\right)}{b} .
$$

Case 3. Consider one last option: $k_{12}^{1}, k_{12}^{2} \geq \frac{a-m c_{1}}{b}$. From the lower level problem, we have:

$$
\begin{array}{lll}
q_{2}^{1}=\frac{a-m c_{1}}{b}, & p_{2}^{1}=m c_{1}, & p_{1}^{1}=a, \\
q_{2}^{2}=\frac{a-m c_{1}}{b}, & p_{2}^{2}=m c_{1}, & p_{1}^{2}=a .
\end{array}
$$

then, we must maximize:

$$
-\operatorname{ecf} k_{12}^{1}-\beta e c f\left(k_{12}^{2}-k_{12}^{1}\right)+\pi_{0}^{*}
$$

Therefore, the best choice is to take

$$
k_{12}^{2}=k_{12}^{2}=\left(a-m c_{1}\right) / b
$$

yielding profits

$$
\pi=\pi_{0}^{*}-\frac{e c f\left(a-m c_{1}\right)}{b}
$$

\section{Ultimate solution}

As before, we now compare in terms of capacity the Transco's profits under the above three cases. It is straightforward to see that the third option will never occur. It then only remains to compare cases 1 and 2 . Subtracting profits in case 1 to those obtained in case 2 , we get:

$$
\begin{aligned}
& {\left[\pi_{0}^{*}+\frac{(3-2 \beta)^{2} e c f^{2}}{16 b}-\frac{e c f\left(a-m c_{1}\right)}{b}\right]-\left[\pi_{0}^{*}+\frac{(3+\beta)^{2} e c f^{2}}{16 b(1+\beta)}-\frac{e c f(a-m c)}{b}\right]=} \\
& \frac{(3-2 \beta)^{2} e c f^{2}}{16 b}-\frac{(3+\beta)^{2} e c f^{2}}{16 b(1+\beta)}= \\
& -\frac{\beta(4 \beta+3)(3-\beta) e c f^{2}}{16 b(1+\beta)}<0 .
\end{aligned}
$$


Therefore, the Transco would prefer case 1 and its optimal choices are given by:

$$
\begin{gathered}
k_{12}^{1}=k_{12}^{2}=\frac{a-m c_{1}}{b}-\frac{(3+\beta) e c f}{4 b(1+\beta)} \\
F^{1} N=\gamma\left[\left(p_{2}^{0}-p_{1}^{0}\right) q^{*}+F^{0} N\right]-\left(a-b k_{12}^{1}-m c_{1}\right) q^{*} \\
F^{2} N=(\gamma)^{2}\left[\left(p_{2}^{0}-p_{1}^{0}\right) q^{*}+F^{0} N\right]-\left(a-b k_{12}^{2}-m c_{1}\right) q^{*}
\end{gathered}
$$




\section{References}

Bertoletti, P., And Poletti, C. (1997) Welfare Effects of Discriminatory Two-Part Tariffs Constrained by Price Caps, Economics Letters, 56: 292-298.

Hogan, W., Rosellón, J. And Vogelsang, I. (2010) Toward a Combined MerchantRegulatory Mechanism for Electricity Transmission Expansion, Journal of Regulatory Economics, Springer, 38(2): 113-143.

Laffont, J. And Tirole, J. (1996) Creating Competition Through Interconection: Theory and Practice, Journal of Regulatory Economics, Springer, 10: 227-256.

Laguna, E. (2012) Regulación del Mercado de Transmisión Eléctrica, Efectos Distributivos, Tesina de Maestría, Centro de Investigación y Docencia Económicas.

Loeb, M. And Magat, W.A. (1979) A Decentralized Method of Utility Regulation, Journal of Law and Economics, 22(2): 399-404.

Rosellón, J., Myslíková, Z. And Zenón, E. (2011) Incentives for Transmission Investment in the PJM Electricity Market: FTRs or Regulation (or both?), Utilities Policy, Elsevier, Volume 19, Issue 1: 3-13.

Rosellón, J., Vogelsang, I. And Weigt, H. (2012)Long-run Cost Functions for Electricity Transmission, The Energy Journal, Vol. 33, No. 1.: 131-160.

Rosellón, J. And Weigt, H. (2011) A Dynamic Incentive Mechanism for Transmission Expansion in Electricity Networks: Theory, Modeling, and Application, The Energy Journal, Vol. 32, No. 1: 119-148.

Schill, W., Rosellón, J. And Egerer, J. (2011) Regulated Expansion of Electricity Transmission Networks: the Effects of Fluctuating Demand and Wind Generation, DIW Berlin Discussion Papers No. 1109.

Sibley D. (1989) Asymmetric Information, Incentives and Price-Cap Regulation, RAND Journal of Economics, 20(3): 392-404.

Vogelsang, I. (1989) Two-Part Tariffs as Regulatory Constraints, Journal of Public Economics, 39(1): 45-66. 
Vogelsang, I. (2001) Price Regulation for Independent Transmission Companies, Journal of Regulatory Economics, 20(2): 141-165.

Zenón, E. y Rosellón, J. (2012) Optimación de las Redes de Transmisión Eléctrica en Norteamérica, Teoría y aplicaciones, El Trimestre Económico, vol. LXXIX (3), núm. 315 575-600. 